\title{
Renal cell carcinoma metastasis to the vocal cord: A case report
}

\author{
Signe B. Nielsen*1, Christer Z. Swan ${ }^{1,2}$ \\ ${ }^{1}$ Department of Otorhinolaryngology and Head \& Neck Surgery, Aarhus University Hospital, Aarhus, Denmark \\ ${ }^{2}$ Institute of Clinical Medicine, Aarhus University, Aarhus, Denmark
}

Received: August 7, 2017

Accepted: October 8, 2017

Online Published: October 20, 2017

DOI: $10.5430 / \operatorname{css} . v 3 n 4 p 11$

URL: https://doi.org/10.5430/css.v3n4p11

\begin{abstract}
Background: Approximately $15 \%$ of renal cell carcinoma (RCC) cases develop extracranial head and neck metastases. Metastatic lesions to the larynx from outside the head and neck region are rare.

Methods: We report an unusual case of RCC metastatic to the left vocal cord, in a 57-year-old female. The patient suffered from metastatic RCC, detected 11 months prior to onset of hoarseness, which was her only symptom of glottic metastasis. The tumor was radically excised applying direct laryngoscopy.

Results: Histopathologic examination revealed metastasis of RCC clear cell type.

Conclusions: Glottic metastases do occur in patients with metastatic RCC and laryngeal symptoms, such as persistent hoarseness, should prompt otolaryngological examination.
\end{abstract}

Key Words: Neoplasm metastasis, Vocal cords, Renal cell carcinoma, Head and neck neoplasms, Hoarseness

\section{INTRODUCTION}

Metastatic lesions to the larynx from outside the head and neck region are uncommon and metastatic neoplasms from any region account for only $0.1 \%$ to $0.4 \%$ of all laryngeal tumors. ${ }^{[1]}$ Metastasis to the larynx most often originates from melanomas $(29 \%)$ or carcinomas derived from the kidney $(25 \%)$, gastrointestinal tract (14\%), lung (9\%), breast $(8 \%)$, and prostate $(5 \%)$. Metastatic lesions to the larynx primarily affect the supraglottic region $(35 \%-40 \%)$, followed by the subglottic region $(10 \%-20 \%)$ and glottis $(5 \%-10 \%) .^{[2]}$

Renal cell carcinomas (RCC) comprise only $2 \%-3 \%$ of all adult malignant tumors. ${ }^{[3,4]}$ Distant metastases from RCC, however, are common and may involve any region of the body. ${ }^{[5,6]}$ Approximately $15 \%$ of RCC cases develop extracranial head and neck metastases, and initial symptoms of RCC due to metastatic disease to this region have been reported in as many as $7.5 \%$.

$\mathrm{RCC}$ is the third most common infraclavicular tumor to metastasize to the head and neck region following breast and lung carcinomas. ${ }^{[5]}$

We present a case of an unusual RCC metastasis located to the left plica vocalis, a condition only described once before in the literature. ${ }^{[7]}$

\section{CASE REPORT}

A 57-year-old woman suffering increasing fatigue during a period of six months was referred to a full-body magnetic resonance imaging (MRI)-scan on suspicion of occult cancer. MRI revealed a tumor in the right kidney, bilateral lung

\footnotetext{
*Correspondence: Signe B. Nielsen; Email: signnils@ rm.dk; Address: Department of Otorhinolaryngology and Head \& Neck Surgery, 1 st Floor, Building 10, Aarhus University Hospital, Nørrebrogade 44, 8000 Aarhus C, Denmark.
} 
metastases, a cystic tumor process in the retroperitoneum, as well as a suspicious process in the $12^{\text {th }}$ thoracic vertebrae (Th12), and a cyst in the liver. One month later a follow-up computerized axial tomography (CT)-scan showed growth of lung metastases and expansion of the process in Th12, highly suspicious of osteolytic metastasis (see Figure 1).

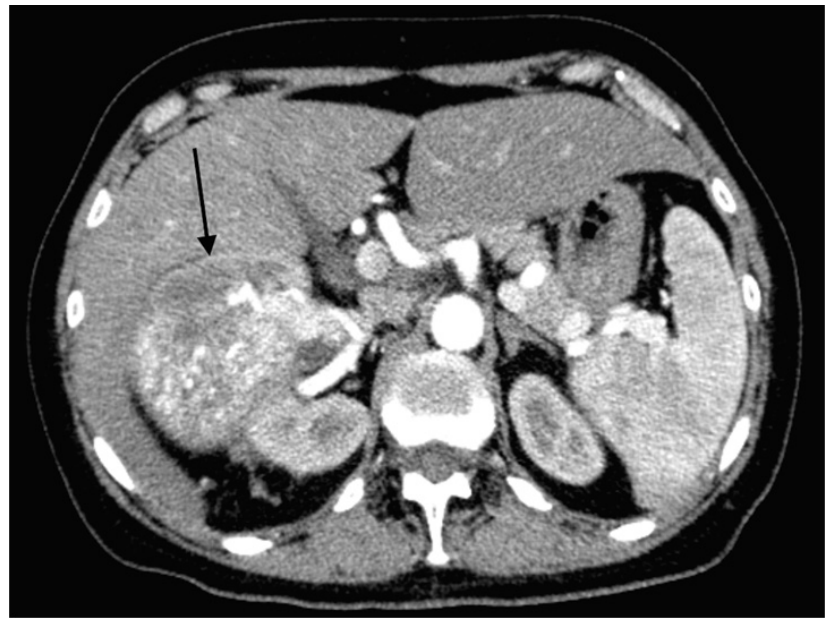

Figure 1. Primary tumor

Axial contrast enhanced CT scan of a 57-year old female showing a heterogeneous contrast enhanced right renal mass (arrow) representing a RCC of clear cell type

Total nephrectomy, adrenalectomy, and lymph node extirpation was performed. Histopathologic examination showed clear cell RCC along with free resection margins, and no invasion of the adrenal gland or lymph nodes. The tumor $(50 \mathrm{~mm} \times 95 \mathrm{~mm})$ was pathologically classified as pT2pN0

The patient was referred to the Department of Oncology at Aarhus University Hospital for further treatment as bone scintigraphy revealed pathologically active bone turnover in Th12 and the right first costa, resembling bone metastases. The patient appeared healthy at time of diagnosis, with an estimated Karnowsky performance score of 100.

First line curative-intended chemo immunotherapy was initiated in accordance with national guidelines. Treatment consisted of interleukin-2, alfa-interferon and angiogenesis inhibitor. Immunotherapy was complicated by side effects and therefore substituted by multi-targeted tyrosine kinase inhibitor. During the course of treatment the patient suffered a pathologic humerus fracture, and progression of metastatic disease was confirmed following a CT scan of the thorax, abdomen and pelvis. Treatment approach was therefore changed from curative to palliative.

Shortly after change of treatment, the patient was admitted to hospital with symptoms mimicking an infection. Dry cough was observed and hoarseness evolved. A chest $X$-ray showed progression in lung metastases and $X$-ray of the right arm revealed progression in osteolytic metastases in the right humerus. Due to persistent hoarseness the patient was referred to the Department of Otorhinolaryngology and Head \& Neck Surgery at Aarhus University Hospital. The patient complained of hoarseness and periods of aphonia during the past one and a half months. There were no other symptoms from the head and neck region, such as dysphagia, dyspnoea, pain, or tendency to clear the throat.

Upon preliminary examination in the outpatient clinic respiration was effortless and without stridor. The voice was weak, and described as almost aphonic. Fiberoptic laryngoscopy revealed a pendulating, reddish, round, benign-looking tumor, with a diameter of $8 \mathrm{~mm}-10 \mathrm{~mm}$, located to the inferior and anterior part of the left vocal cord. Vocal cord mobility was normal.

The benign appearing, polyp-like tumor was extirpated in general anesthesia applying direct laryngoscopy, and no tumor remnant was visible following the procedure. Tumor localization was confirmed to be inferomedially of the anterior half of the left plica vocalis, and delineated as round and red with an uneven surface. The diameter was less than one centimeter. The posterior part of the vocal cords including the posterior commissure was without pathological findings. Examination of the oral cavity, pharynx, larynx, and esophageal entrance and palpation of the floor of the mouth, base of the tongue, tonsillar regions, and neck, revealed no further pathology.

The patient was discharged the following day, and instructed to perform regular deep breaths and to rest her voice.

Two weeks after surgery the patient was seen in the outpatient clinic, and presented with a well-functioning voice and no stridor. Flexible fiberoptic laryngoscopy showed complete healing of the left vocal cord and no tumor.

Histopathologic examination revealed metastasis of clear cell RCC infiltrating vocal cord squamous epithelium and stroma (see Figure 2).

Follow-up was scheduled three months later, however the patient died prior to examination, of causes unrelated to her laryngeal metastasis.

\section{Discussion}

In our case report we demonstrate a rare solitary RCC metastasis located to the left plica vocalis. The report illustrates the metastatic potential of RCC, as the vocal cords have low blood and lymph perfusion. Further, the finding emphasizes the relevance of promptly addressing new symptoms from the head neck region in patients either actively treated for 
or with a history of RCC, as metastatic disease may manifest several years after treatment of the primary tumor. ${ }^{[3,8]}$ Typically, glottic lesions manifest as hoarseness, as was our patients only complaint, whereas supraglottic lesions often present with globus sensation, dysphagia or change in voice quality, and subglottic lesions tend to compromise the airway. Further, highly vascular tumors, such as RCC metastases, often result in hemoptysis. ${ }^{[2]}$

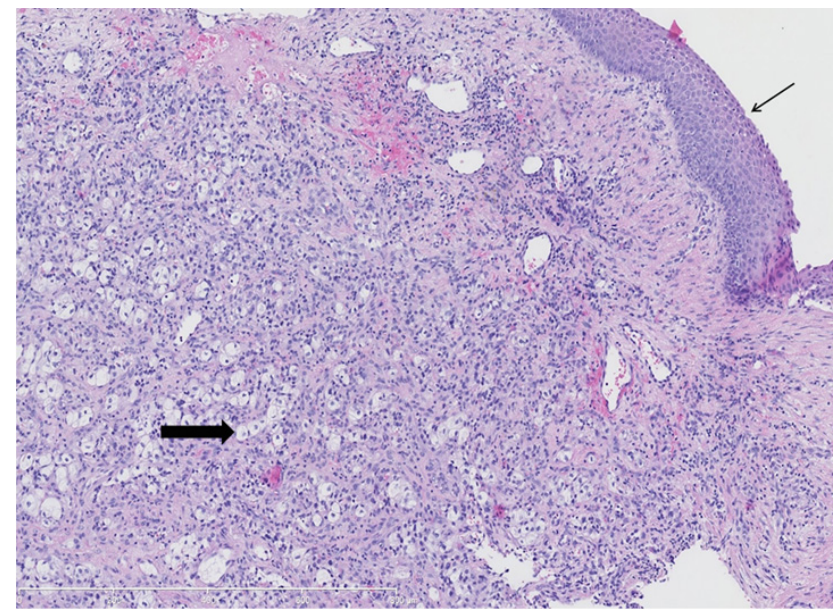

Figure 2. RCC metastasis to the vocal cord

Hematoxylin and eosin stained micrograph of a metastasis located on the left vocal cord, which originated from a RCC of clear cell type. Metastatic clear cells can be seen infiltrating the stroma of the left plica vocalis (thick arrow), which is lined by squamous epithelium on the surface (thin arrow)

Eleven reports on RCC metastases to the larynx were found when reviewing the literature (see Table 1).

Most studies described solitary metastasis to either the supraglottic, ${ }^{\left[{ }^{-12]}\right.}$ or subglottic region, ${ }^{[13-15]}$ two studies described involvement of both the supraglottic and glottic regions, ${ }^{[16,17]}$ and one described metastases involving all three regions of the larynx. ${ }^{[3]}$

Table 1. Case reports on laryngeal metastases of RCC and corresponding anatomical localization

\begin{tabular}{|c|c|}
\hline $\begin{array}{l}\text { Author and year of } \\
\text { publication }\end{array}$ & $\begin{array}{l}\text { Laryngeal region of } \mathrm{RCC} \\
\text { metastasis }\end{array}$ \\
\hline Rossini et al. $2004^{[1]]}$ & Supraglottic \\
\hline Dee et al. $2000^{[9]}$ & Supraglottic \\
\hline Mochimatsu et al. $1993^{[10]}$ & Supraglottic \\
\hline Miyamoto et al. $1973^{[12]}$ & Supraglottic \\
\hline Mehdi et al. 2012 ${ }^{[16]}$ & Supraglottic and glottic \\
\hline Navarro et al. $2000^{[17]}$ & Supraglottic and glottic \\
\hline Maung et al. $1987^{[7]}$ & Glottic \\
\hline Allan Fields, J. $1966^{[13]}$ & Subglottic \\
\hline Ferlito et al. $1988^{[15]}$ & Subglottic \\
\hline Greenberg et al. $1992^{[14]}$ & Subglottic \\
\hline Demir et al. $2012^{[3]}$ & Supraglottic, glottic and subglottic \\
\hline
\end{tabular}

To our knowledge solitary RCC metastasis located to the glottis, has only been described once before, namely by Maung et al., who presented a case with involvement of the anterior part of the right plica vocalis. ${ }^{[7]}$

Metastasectomy has been shown to contribute to long-term survival in patients with metastatic RCC, and several studies suggest it be included as part of life-sustaining treatment protocols. ${ }^{[6]}$ The glottic metastasis presented in our case, was excised both in order to clarify its etiology and to ease the patients' symptoms. As metastasis to the head and neck region may affect respiratory and vocal function as well as swallowing, it seems reasonable to address lesions in this region aggressively.

\section{CONFlicts OF InTEREST Disclosure}

The authors declare they have no conflicts of interest.

\section{REFERENCES}

[1] Puxeddu R, Pelagatti CL, Ambu R. Colon adenocarcinoma metastatic to the larynx. Eur. Arch. Otorhinolaryngol. 1997; 254: 353-5. PMid: 9298673. https://doi.org/10.1007/BF02630729 http://dx .doi.org/10.1186/1471-2261-3-9

[2] Barnes L. Metastases to the head and neck: an overview. Head. Neck. Pathol. 2009; 3: 217-24. PMid: 20596975. https ://doi .org/10 .1007/s12105-009-0123-4

[3] Demir L, Erten C, Somali I, et al. Metastases of renal cell carcinoma to the larynx and thyroid: Two case reports on metastasis developing years after nephrectomy. Can. Urol. Assoc. J. 2012; 6: E209-12. PMid: 23093648. https://doi.org/10.5489/cuaj.11255

[4] Donskov F. Interleukin-2 based immunotherapy in patients with metastatic renal cell carcinoma. Dan. Med. Bull. 2007; 54: 249-65. PMid: 18208677.

Published by Sciedu Press
[5] Pritchyk KM, Schiff BA, Newkirk KA, et al. Metastatic renal cell carcinoma to the head and neck. Laryngoscope. 2002; 112: 1598-602. PMid: 12352670. https://doi.org/10.1097/00005537-200 209000-00012

[6] Ljungberg B. The role of metastasectomy in renal cell carcinoma in the era of targeted therapy. Curr. Urol. Rep. 2013; 14: 19-25. PMid: 23212738. https://doi.org/10.1007/s11934-012-0293-6

[7] Maung R, Burke RC, Hwang WS. Metastatic renal carcinoma to larynx. J. Otolaryngol. 1987; 16: 16-8. PMid: 3560301.

[8] Ziari M, Shen S, Amato RJ, et al. Metastatic renal cell carcinoma to the nose and ethmoid sinus. Urology. 2006; 67: 199. PMid: 16413368. https://doi.org/10.1016/j . urology.2005.07.052

[9] Dee SL, Eshghi M, Otto CS. Laryngeal metastasis 7 years after radical nephrectomy. Arch. Pathol. Lab. Med. 2000; 124: 1833-4. PMid: 11100069 . 
[10] Mochimatsu I, Tsukuda M, Furukawa S, et al. Tumours metastasizing to the head and neck-a report of seven cases. J. Laryngol. Otol. 1993; 107: 1171-3. PMid: 8289013. https://doi.org/10.1017/S002 2215100125599

[11] Rossini M, Bolzoni A, Piazza C, et al. Renal cell carcinoma metastatic to the larynx. Otolaryngol. Head. Neck. Surg. 2004; 131: 1029-30. PMid: 15577815 . https://doi.org/10.1016/j.otoh ns.2004.03.019

[12] Miyamoto R, Helmus C. Hypernephroma metastatic to the head and neck. Laryngoscope. 1973; 83: 898-905. PMid: 4711327. https://doi.org/10.1288/00005537-197306000-00007

[13] Fields JA. Renal carcinoma metastasis to the larynx. Laryngoscope. 1966; 76: 99-101.
[14] Greenberg RE, Cooper J, Krigel RL, et al. Hoarseness; a unique clinical presentation for renal cell carcinoma. Urology. 1992; 40: 159-61. https://doi .org/10.1016/0090-4295(92) 90518-2

[15] Ferlito A, Caruso G, Recher G. Secondary laryngeal tumors. Report of seven cases with review of the literature. Arch. Otolaryngol. Head. Neck. Surg. 1988; 114: 635-9. PMid: 3284547. https : //doi.org/10.1001/archotol.1988.01860180049028

[16] Mehdi I, Satayapal N, Abdul Aziz MI, et al. Renal Cell Carcinoma metastasizing to larynx: a case report. Gulf J. Oncolog. 2012; 11: 70-4.

[17] Navarro F, Vicente J, Villanueva MJ, et al. Metastatic renal cell carcinoma to the head and neck area. Tumori. 2000; 86: 88-90. PMid: 10778775 . 